\title{
Determination of total phenolic compound content and antioxidant activity in cherry species and cultivars
}

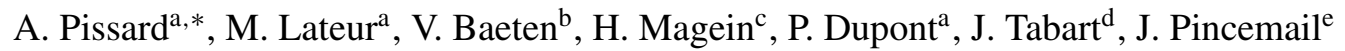 \\ and C. Kevers ${ }^{\mathrm{d}}$ \\ ${ }^{a}$ Walloon Agricultural Research Center (CRA-W), Biodiversity and Plant Breeding Unit, Gembloux, Belgium \\ ${ }^{\mathrm{b}}$ Walloon Agricultural Research Center (CRA-W), Food and Feed Quality Unit, Gembloux, Belgium \\ ${ }^{\mathrm{c}}$ Walloon Agricultural Research Center (CRA-W), Crop Production Systems Unit, Gembloux, Belgium \\ ${ }^{\mathrm{d}}$ Plant Molecular Biology and Biotechnology Unit, CEDEVIT (ASBL), Plant Biology Institute, \\ University of Liège, Sart-Tilman, Liège, Belgium \\ ${ }^{\mathrm{e}}$ Centre de Recherche Expérimentale du Département de Chirurgie (CREDEC), University of Liège, Sart-Tilman, \\ Liège, Belgium
}

Received 16 July 2015; accepted 5 November 2015

\begin{abstract}
.
BACKGROUND: Several studies have shown that cherries, especially sour cultivars, contain substantial amounts of phenolic compounds.

OBJECTIVE: This study aims to (i) analyze the total phenolic compound (TPC) content and the antioxidant capacity (AC) of a large range of cultivars using the same methodology in one laboratory, and (ii) determine the possible relationship between agronomic characteristics and AC.

METHODS: A total of 245 samples including sweet, sour and hybrid cultivars from our collections were harvested at their optimum maturity and characterized according to their TPC, DPPH and ORAC values.

RESULTS: The TPC content and DPPH and ORAC values varied greatly among the cherries, with the sour cultivars presenting higher levels than the sweet ones. The PCA plot showed a slight grouping by species and confirmed the high TPC content level in sour cultivars. The bi-colored cultivars had lower TPC and antioxidant capacity (AC) values than dark-colored ones, indicating that coloration could give an indication of the $\mathrm{AC}$ of fruits. No significant relationship between the agronomic and chemical properties was highlighted.

CONCLUSIONS: Cherry fruits, especially from sour cultivars, represent an important source of bioactive compounds and could attract new interest as a 'functional food'.
\end{abstract}

Keywords: Sweet cherries, sour cherries, antioxidant capacity, total phenolic compounds

\footnotetext{
*Corresponding author: A. Pissard, Walloon Agricultural Research Center (CRA-W), Biodiversity and Plant Breeding Unit, Rue de Liroux, 4, 5030 Gembloux, Belgium. Tel.: +32 81620 316; E-mail: a.pissard@ cra.wallonie.be.
} 


\section{Introduction}

The most important species of cherries belonging to the subgenus Cerasus are Prunus avium L., known as 'sweet cherry', and P. cerasus L., known as 'sour cherry' or 'tart cherry'. In many fruit production areas in the world, sweet cherries are the first fresh fruits of the season, eaten mainly as a fresh, non-processed product and popular with consumers because of their quality. Physical and chemical characteristics are very important for cherry fruit production as they directly influence consumer acceptability. Although the concept of fruit quality depends on the product itself and on consumer preference, it is widely accepted that the main characteristics related to sweet cherry quality are fruit weight, color, firmness, sweetness, sourness, flavor and aroma $[1,2]$. The sweetness is due to the presence of sugars, glucose and fructose mainly, followed by sorbitol and sucrose [3-5]. Sourness is due mainly to the presence of malic acid. Consumer acceptability seems to depend on the ratio between sugar and acid content [1]. Firmness appears to be the other major consideration in acceptability. The sour cherry is a temperate fruit of marginal importance, but it could attract new interest as a 'functional food' because its high antioxidant capacity (AC) values [6].

There are important differences in the physical and chemical characteristics of cherry cultivars. The main sources of variation are the cultivar itself and the ripening stage, both of which have a significant influence on fruit quality $[1,2,5]$. Soluble solids and titrable acidity provide useful information for growers during the ripening process of sweet cherries. Skin color is the most common parameter that growers and consumers use to assess the quality and maturity of fresh and processed cherries [7]. Color is a relevant characteristic, especially in cherries used for processing, because it has a direct influence on the quality of finished products. The development of the red color, influenced mainly by the concentration and distribution of anthocyanins in the skin, is used as an indicator of quality and ripening. Many studies have been done on anthocyanins and color change in sweet cherries, but studies on sour cherries are rare [8].

Both types of cherries (sweet and sour) contain substantial amounts of total phenolic compounds (TPC), including anthocyanins [7,9]. Several studies have shown that sour cherries contain a higher level of TPCs and anthocyanins than sweet cherries [10]. Comparative data on sweet and sour cherry composition using the same analytical methodologies, however, are limited [11]. Some studies have shown high variability in TPC content in cultivars [5, 10]. In addition, TPCs and anthocyanins are not uniformly distributed in the fruit tissue. Chaovanalikit and Wrolstad [11] showed that they were concentrated in the skin, but there are differences in distribution among varieties; in some varieties, they are present in both the skin and flesh, but in others they are limited to the skin.

Phenolic compounds contribute to the sensory properties and AC of fruits. Epidemiological studies have shown that eating food rich in polyphenolic compounds has several positive effects on human health. Specifically, cherry consumption has been reported to alleviate arthritis and gout-related pain [12]. It has also been shown that sour and sweet cherry anthocyanins have the potential to reduce the proliferation of human colon cancer cells [13], to promote strong antidegenerative activity in neuronal cells [10] and to play a beneficial role in the treatment of inflammatory pain $[1,14]$. According to [12], the AC of anthocyanins from sour cherries was comparable to some commercial antioxidants. The health benefits of sweet and sour cherries and the effect of their bioactive components on human diseases such as cancer, cardiovascular disease, diabetes, inflammatory diseases, and Alzheimer's disease have been reviewed recently $[15,16]$.

As in the case of other small dark berries, cherries are good source of bioactive compounds, including vitamin $\mathrm{C}$ and TPCs, which account for high AC values. The complexity of techniques used to evaluate total AC in food was described by [17]. A variety of techniques have been used to induce and catalyze oxidation and to measure the endpoint of oxidation. Two widely used in vitro methods are DPPH and ORAC. DDPH (2.2-diphenyl-1picrylhydrazyl) assay is based on the ability of the stable 2,2-diphenyl-1-picryhydrazyl free radical to react with hydrogen donors. The presence of antioxidant species leads to the disappearance of chromogenic free radicals. This disappearance can be monitored spectrometrically. In the oxygen radical absorbance capacity (ORAC) assay, free radicals are generated at a constant rate through the thermal decomposition of 2.2/-azobis (2-amino-propane) dihydrochloride (AAPH). This assay is more sensitive (higher value, large scale) than the other assays. In the past, 
ORAC values appear to have been exaggerated and their health claims unsupported. These values, indicating AC, are not relevant to the effects of specific bioactive compounds, including polyphenols, on human health. They should simply be considered as data reflecting overall AC only in vitro. Antioxidant molecules in food have a wide range of functions, many of which are unrelated to the ability to absorb free radicals. Nevertheless, some studies have recently promoted the relevance of ORAC in human health research [18].

Research on cherry species at CRA-W has various purposes. Two main cherry orchards have been established and for many years have been managed in a different way. One orchard grows commercial cultivars or new genotypes of sweet cherries (P. avium) from around the world, selected for commercial purposes, in order to assess their agronomic performance in our environmental conditions. The second orchard focuses on genetic resource conservation and includes diverse types of cherry $($ P. avium L., P. cerasus L., and unspecified $P$. $\times$ avium hybrids). It is likely that the great variability in the two orchards in terms of cherry types and morphological characteristics (mainly coloration) influences their TPC content and AC.

The aim of the study was to analyze the TPC content and AC of a large range of sweet and sour cherry cultivars in our collections using the same methodology and conducting the work in one laboratory. A secondary objective was to determine the possible relationship between sensory and agronomic characteristics and AC. This study is part of our work on the evaluation and promotion of fruits with a high nutritional quality intended for direct consumption, processing or breeding purposes.

\section{Materials and method}

\subsection{Plant materials}

The cherries were obtained from two orchards at CRA-W. A total of 245 samples were harvested over two growing seasons (2013 and 2014), made up of 213, 25 and 7 samples of P. avium, P. cerasus L., and $P$. $\times$ avium, respectively. Due to different fruit settings, 101 cultivars were harvested once and 69 were harvested at least twice in 2013 and 2014.

The samples were collected over a few weeks in order to harvest each variety at its optimum maturity stage. For each variety, fruits of similar optimum ripening stage were selected in order to achieve sample uniformity.

The skin color of all the cherries was assessed according to an international color chart. In addition, a detailed description accompanied the 182 samples (including 125 cultivars or genotypes) from the orchard growing commercial cherries. The descriptors included country of origin, sugar content (expressed in Brix degree), firmness (deformation of fruits under a constant load of $200 \mathrm{~g}$, expressed in $10^{-1} \mathrm{~mm}$ ), maturity (earliness compared with the reference cultivar Burlat and expressed in days before or after the harvest date of Burlat), weight (expressed in g), cracking level (expressed as a \% of fruits with a skin break $>2 \mathrm{~mm}$ ) and the flesh and juice colors (determined visually according to international color charts).

\subsection{Sample preparation}

Immediately after harvest, about 10 fruits per cultivar were processed for chemical analyses. The cherry seeds were carefully removed by hand and the edible parts of the fruits were directly frozen with liquid nitrogen and crushed using a blender into a fine and homogeneous powder. Two grams of powder were weighed and extracted with $4 \mathrm{~mL}$ methanol. The extracts were used to determine TPC content and AC.

\subsection{Determining total phenolic compound content and antioxidant activity}

The total phenolic compound content and antioxidant activity were determined for all samples. The TPC was determined using the Folin-Ciocalteu method [19]. First, $3.6 \mathrm{~mL}$ of appropriate dilution were mixed with 
$0.2 \mathrm{~mL}$ of Folin-Ciocalteu reagent (VWR International). After incubation for $3 \mathrm{~min}, 0.8 \mathrm{~mL}$ of sodium carbonate solution (VWR International; $20 \% \mathrm{w} / \mathrm{v}$ ) was added. The mixture was heated at $100^{\circ} \mathrm{C}$ for $1 \mathrm{~min}$. The absorbance at $750 \mathrm{~nm}$ was measured after cooling. A standard curve was created with gallic acid (Sigma-Aldrich, USA). The results were expressed as mg of gallic acid equivalents (GAE) per gram of fresh weight (FW).

All the AC assays were carried out on a Victor3 (Perkin Elmer Inc. USA) 96-well plate reader (see [20], for detailed procedure). For the DPPH assays (absorbance decrease due to the reduction of the radical 2,2-diphenyl1-picrylhydrazyl), a fresh stock solution was prepared daily by stirring $75 \mathrm{mg}$ DPPH (Sigma-Aldrich, USA) in $1 \mathrm{~L}$ methanol (VWR International) for $30 \mathrm{~min}$ in the dark and warmed to $30^{\circ} \mathrm{C}$. In the assay, $0.1 \mathrm{~mL}$ extract, standard (50-100 $\mu$ M Trolox) or blank (methanol), and $0.2 \mathrm{~mL} \mathrm{DPPH} \mathrm{solution} \mathrm{were} \mathrm{mixed.} \mathrm{The} \mathrm{absorbance} \mathrm{at} 520 \mathrm{~nm}$ of samples, standards and blanks was determined after exactly $5 \mathrm{~min}$. For the ORAC assays, AAPH (Sigma-Aldrich, USA) was used as a peroxyl radical generator and fluorescein (VWR International) as a fluorescent probe. Filters were used to excite at a wavelength of $485 \mathrm{~nm}$ and to measure at an emission wavelength of $535 \mathrm{~nm}$. An amount of $175 \mu \mathrm{L}$ of a mixture of fluorescein $(3 \mu \mathrm{M})$ and AAPH $(221 \mathrm{mM})$ was injected into each well of the microplate, and $25 \mu \mathrm{L}$ of diluted sample, blank or Trolox calibration solution (50 to $200 \mu \mathrm{M}$ ) was added. The fluorescence at $37^{\circ} \mathrm{C}$ was measured every $2 \mathrm{~min}$ for $1 \mathrm{~h}$. The final ORAC value was calculated from the net area under the fluorescence decay curve. For these two methods (DPPH and ORAC assays), Trolox [( \pm ) 6-hydroxy-2,5,7,8tetramethylchromane-2-carboxylic acid; Fluka Chemie $\mathrm{GmbH}$, Switzerland] was used as a standard. The AC was expressed in $\mu \mathrm{mol}$ Trolox equivalents (TE) per gram of fresh weight (FW). All the analyses were conducted in triplicate. The analytical methods used in this study had been validated internally, including the ORAC assay [21].

\subsection{Statistical analyses}

Descriptive statistics and correlation coefficients between parameters were calculated, taking all the samples into account. The results were processed using a one-way analysis of variance (ANOVA). The sources of variation were types and coloration. Significance among groups was determined using the post-hoc Tukey's Honest Significance Differences (HSD) test at $P<0.05$. In order to identify any influence of growing season on AC and TPC content, the cultivars harvested twice in 2013 and 2014 were analyzed using a Student $t$-test for paired samples. Principal component analyses (PCA) were performed in order to provide appropriate visualization of the dataset in a reduced dimension. The analyses were realized using Unscrambler software (Camo Software AS, Norway) after normalization of the data (Unit Vector Normalization).

Finally, in order to determine the relationship between sensory and agronomic characteristics and the AC of the cultivars, analyses were conducted using only the 182 samples from the orchard growing commercial cultivars. Correlations between all variables (agronomic and chemical variables) were calculated and principal component analyses were performed.

\section{Results and discussion}

\subsection{Total phenolic compound content and total antioxidant capacity}

\subsubsection{Sweet versus sour cherries}

Mean TPC content for all 245 samples analyzed was $1.79 \mathrm{mg}$ GAE/g FW. A large variation in value was observed among cultivars, with values ranging from 0.52 to $7.56 \mathrm{mg} \mathrm{GAE} / \mathrm{g}$ FW.

Sweet cherry cultivars contained a significantly lower level of TPCs than sour cherry cultivars (Table 1). The mean TPC content of sweet cherries was $1.56 \mathrm{mg}$ GAE/g FW, whereas it reached $3.72 \mathrm{mg} \mathrm{GAE} / \mathrm{g}$ FW for sour cultivars. The TPC content in sweet cherries varied from 0.52 to $5.88 \mathrm{mg} \mathrm{GAE} / \mathrm{g} \mathrm{FW}$, but ranged from 1.20 to $7.56 \mathrm{mg} \mathrm{GAE} / \mathrm{g} \mathrm{FW}$ in sour cultivars. The $P$. $\times$ avium hybrids showed an intermediate level of TPC content, with an average of $1.93 \mathrm{mg}$ GAE/g FW. 
Table 1

Mean antioxidant capacity (AC) determined by DPPH and ORAC assays ( $\mu \mathrm{mol} \mathrm{TE} / \mathrm{g} \mathrm{FW}$ ) and total phenolic compound (TPC) content (mg GAE/g FW) in cherry samples according to type (P. avium, $P$. cerasus, and $P$. $\times$ avium)

\begin{tabular}{lcccc}
\hline Type & $\mathrm{n}$ & $\mathrm{DPPH}(\mu \mathrm{mol} \mathrm{TE} / \mathrm{g} \mathrm{FW})$ & ORAC $(\mu \mathrm{mol} \mathrm{TE} / \mathrm{g}$ FW $)$ & TPC $(\mathrm{mg}$ GAE/g FW $)$ \\
\hline P. avium & 212 & $3.69 \pm 2.35^{\mathrm{a}}$ & $48.41 \pm 27.33^{\mathrm{a}}$ & $1.56 \pm 0.82^{\mathrm{a}}$ \\
P. cerasus & 25 & $5.45 \pm 3.93^{\mathrm{b}}$ & $79.64 \pm 49.12^{\mathrm{b}}$ & $3.72 \pm 1.75^{\mathrm{b}}$ \\
$P . \times$ avium & 7 & $3.33 \pm 1.89^{\mathrm{a}} \mathrm{b}$ & $58.98 \pm 32.21^{\mathrm{a}, \mathrm{b}}$ & $1.93 \pm 1.29^{\mathrm{a}}$ \\
Mean & & $3.86 \pm 2.59$ & $51.91 \pm 31.76$ & $1.79 \pm 1.16$ \\
\hline
\end{tabular}

Means within a column with the same letter are not significantly different $(P \leq 0.05)$.

The higher TPC content in sour cherries compared with sweet ones has been reported in other studies [10, 15, 22]. In their review, [15] reported TPC values of $1.09 \mathrm{mg} / \mathrm{g}$ and $2.28 \mathrm{mg} / \mathrm{g}$ in sweet and sour cherries, respectively. The higher levels of TPCs in sour cherries were attributed to higher concentrations of anthocyanins and hydroxicinnamic acids.

Compared with the literature, our ranges of values for sweet and sour cherries were particularly high. In most cases, they were higher than those reported in similar studies. TPCs in sweet and sour cherries ranging from 0.92 to 1.46 and from 1.46 to $3.12 \mathrm{mg} \mathrm{GAE} / \mathrm{g}$ respectively were reported by [10]. Low TPC values in sweet cherry cultivars, ranging from 0.44 to $0.88 \mathrm{mg} / \mathrm{g} \mathrm{FW}$ reported by [4]. A recent study reported a TPC content ranging from 0.84 to $1.62 \mathrm{mg} \mathrm{GAE} / \mathrm{g} \mathrm{FW}$ for 24 sweet cherry cultivars [5]. In [22], TPC content ranged from 0.28 to $1.06 \mathrm{mg} / \mathrm{g} \mathrm{FW}$ for sweet cherries and from 0.70 to $2.41 \mathrm{mg} / \mathrm{g}$ for sour cherries collected from local markets. Compared with our values, only [23] reported a higher range of TPC content in 22 sour cherry cultivars (from 4.62 to $10.49 \mathrm{mg} / \mathrm{g}$ GAE FW).

As highlighted in various studies $[1,8,24]$, maturity stage at harvest can influence fruit quality. The study carried out by [24] showed an increase in TPCs as maturity advanced and observed the same levels of TPCs ( 0.70 to $1.5 \mathrm{mg} / \mathrm{g} \mathrm{FW}$ ) in cherries harvested at a commercial harvesting stage ('Stage S2 $)$ ) as those reported in the literature $[10,25]$. It should be noted that our samples were not picked at the commercial harvesting stage, but at the optimal harvest date (corresponding to 'Stage S3') i.e. after the commercial harvesting stage. Therefore, it is possible that they contained slowly higher levels of TPCs than samples analyzed at commercial stage. Comparison with the literature is difficult as most studies deal with samples collected at commercial maturity and/or with local varieties. In addition, as noted by authors $[8,9]$, other pre-harvest factors than ripeness, such as the temperature and the light intensity, may affect the content and the stability of phytochemical in cherries. Finally, some authors suggested that discrepancies between the diverse studies on cherries composition could also be attributed to varying extraction conditions [22].

The DPPH antiradical efficiency values for sour cultivars were significantly higher than for sweet cherries. They reached $5.45 \mu \mathrm{mol} \mathrm{TE} / \mathrm{g} \mathrm{FW}$, whereas for sweet cherries the value was only $3.69 \mu \mathrm{mol} \mathrm{TE} / \mathrm{g}$ FW. The level of DPPH was even lower, albeit slightly, for the $P . \times$ avium hybrids, with a value of $3.33 \mu \mathrm{mol} \mathrm{TE} / \mathrm{g} \mathrm{FW}$.

The ORAC values were also significantly higher for sour cherries than for sweet ones $(79.64 \mu \mathrm{mol} \mathrm{TE} / \mathrm{g} \mathrm{FW}$ compared with $48.41 \mu \mathrm{mol}$ TE/g FW). The hybrids showed an intermediate AC level (58.98 $\mu \mathrm{mol} \mathrm{TE} / \mathrm{g} \mathrm{FW})$. The average ORAC value for sweet cherries in this study was higher than those observed by [5], which ranged from 6.46 to $31.66 \mu \mathrm{mol} \mathrm{TE} / \mathrm{g} \mathrm{FW}$ and by [26], who reported values ranging from 50 to $177 \mu \mathrm{mol} \mathrm{TE} / \mathrm{g}$ dry weight for nine cherry varieties, equivalent to $13.20-35.40 \mu \mathrm{mol} / 100 \mathrm{~g} \mathrm{FW}$.

For the Burlat cultivar, the AC revealed by the ORAC assay reached $40.27 \mu \mathrm{mol} \mathrm{TE} / \mathrm{g} \mathrm{FW}$, whereas [5] obtained a value of $24.52 \mu \mathrm{mol} / \mathrm{g} \mathrm{FW}$. According to the literature, Burlat has a very high anthocyanin concentration and a high AC $[4,27,28]$. Within the range of values obtained in this study, the TPC content and AC for this cultivar were intermediate. Our results suggested that many other cultivars in our collections have higher levels and might therefore present interesting profiles in terms of healthy components. In particular, eight $P$. avium cultivars (the rootstock Abbesse, Royal Tardif, Rouge Tardive, Belge, Cerise de Maubeuge, Lignette, Abbesse de Mouland and 
Cerise Nimal) had very high TPC content levels (more than $3 \mathrm{mg} / \mathrm{g} \mathrm{FW).} \mathrm{Four} \mathrm{of} \mathrm{them} \mathrm{(Abbesse,} \mathrm{Royal} \mathrm{Tardif,}$ Rouge Tardive and Cerise de Maubeuge) also had particularly high levels of AC, as revealed by the ORAC and DPPH assays. These cultivars could be considered in breeding work aimed at creating new cherry cultivars with healthy characteristics.

Our results showed a positive correlation between AC and TPC content. The highest value was observed between DPPH and TPC content $(r=0.82)$, followed by ORAC and TPC content $(r=0.80)$. The AC values measured by both DPPH and ORAC gave a coefficient of correlation of 0.79 . A positive correlation $(r=0.50 ; p-$ value $<0.05)$ between ORAC and TPC content was also reported by [5]. A highly positive correlation $\left(r^{2}=0.99\right)$ between AC and TPCs was shown by [3]. A weak but statistically significant correlation $(r=0.62)$ between AC evaluated with DPPH and TPC content was obtained by [27]. Some authors found that TPCs were a good predictor of antioxidant properties, with a positive correlation of 0.97 and 0.95 using ORAC and Ferric Reducing Antioxidant Power (FRAP), respectively, and proved to be a much better predictor than anthocyanin content (correlation of 0.61 between anthocyanins and ORAC) [11]. They noted, as other authors have done [27], that anthocyanin content alone was not a good predicator of relative AC. Some authors, however, found strong correlations between AC and anthocyanin content [29]. Very high correlation coefficients between ORAC and TPC and total anthocyanin content ( $r=0.99$ and 0.97 , respectively) were also reported by [26]. The results reported by [4] partly confirmed this finding. They showed that the relationship between attributes (AC, TPC content and total anthocyanin content) varied among cultivars, with a large range of correlation values $\left(r^{2}\right.$ from 0.01 to 0.99 ). They reported great variability among cultivars in sensory and chemical attributes and suggested that the $\mathrm{AC}$ of sweet cherries depends on chemical attributes and is cultivar-specific.

Several methods have been developed to measure the total AC of biological samples [13,29]. Many studies have reported on the AC of cherries. Some authors used the DPPH method, but expressed their findings in ascorbic acid equivalent [4]. An improved ORAC assay was used by [6]. Other methods used included FRAP [11, 29] and Trolox Equivalent Antioxidant Capacity (TEAC) [28]. Some studies have used a method in which AC is determined according to the lipophilic and hydrophilic compounds of the samples [24]. Given the wide array of methods and cultivars analyzed in the literature, the results of studies are not always comparable. Several authors have compared the various methods (ORAC, DPPH, FRAP, ABTS) used to estimate AC in fruits and vegetables that have led to different results for crop species and crop laboratories. The values obtained using different methods can be quite similar, as found by [6], or can diverge, because the methods are based on different reaction mechanisms. The different reaction mechanism of the two assays used in this study could explain the different rank order of the cultivars and therefore the intermediate levels of coefficient correlation found in this study.

\subsubsection{Coloration analysis}

The cultivars were divided into three classes according to fruit coloration and color intensity: bi-colored, red, and dark red cultivars. As cherries with a uniform yellow coloration are rare, they were included in the bi-colored class. The mean TPC content and AC values were calculated for each class (Table 2). The results clearly showed that bi-colored (including yellow and yellow-red cultivars) had lower TPC and AC values than red and dark red cultivars. Tukey's HDS test showed that bi-colored and dark red cultivars had significantly different TPC and AC values based on DPPH assays. The AC based on ORAC assays was also higher in dark red cultivars, but the differences were not statistically significant. The cherries with a yellow skin (Merton Glory, Corum, Mac Mar, Rainier and Big Jaune Tardif) had particularly low average levels of AC (1.2 $\mu \mathrm{mol}$ TE/g FW and $30.1 \mu \mathrm{mol}$ TE/g FW for DPPH and ORAC, respectively) and TPC content ( $0.65 \mathrm{mg} \mathrm{GAE} / \mathrm{g} \mathrm{FW})$. These results suggest that the color of a fruit could indicate its AC and TPC levels, which accords with the results of most studies of this subject. Recently, [28] showed that the total content of anthocyanins and flavonoids was higher in red cherries than in bi-colored ones. Other authors also showed that $\mathrm{AC}$ was higher in sweet cherry cultivars with dark fruits [29]. Usenik et al. [4] obtained results that partly confirmed these findings, with the cultivar Burlat having the highest $\mathrm{AC}$ values, but they identified a bi-colored cultivar with a very high $\mathrm{AC}$ value and, conversely, cultivars with dark red fruits with the lowest AC values. 
Table 2

Mean antioxidant capacity (AC) determined by DPPH and ORAC assays ( $\mu \mathrm{mol} \mathrm{TE} / \mathrm{g} \mathrm{FW}$ ) and total phenolic compound (TPC) content (mg GAE/g FW) in cherries according to skin color

\begin{tabular}{lcccc}
\hline Skin color & $\mathrm{n}$ & $\mathrm{DPPH}(\mu \mathrm{mol} \mathrm{TE} / \mathrm{g} \mathrm{FW})$ & ORAC $(\mu \mathrm{mol}$ TE/g FW $)$ & TPC $(\mathrm{mg} \mathrm{GAE} / \mathrm{g} \mathrm{FW})$ \\
\hline Bi-colored & 12 & $1.64 \pm 0.69^{\mathrm{a}}$ & $34.64 \pm 14.26^{\mathrm{a}}$ & $0.92 \pm 0.41^{\mathrm{a}}$ \\
Red & 11 & $2.34 \pm 0.74^{\mathrm{a}, \mathrm{b}}$ & $44.27 \pm 15.11^{\mathrm{a}}$ & $1.90 \pm 0.91^{\mathrm{a}, \mathrm{b}}$ \\
Dark red & 221 & $4.05 \pm 2.64^{\mathrm{b}}$ & $53.23 \pm 32.76^{\mathrm{a}}$ & $1.83 \pm 1.19^{\mathrm{b}}$ \\
Mean & & $3.86 \pm 2.59$ & $51.91 \pm 31.76$ & $1.79 \pm 1.16$ \\
\hline
\end{tabular}

Means within a column with the same letter are not significantly different (Tukey's HSD test, $P \leq 0.05$ ).

Table 3

Mean antioxidant capacity (AC) determined by DPPH and ORAC assays ( $\mu \mathrm{mol}$ TE/g FW) and total phenolic compound (TPC) content (mg GAE/g FW) in cherries according to flesh color

\begin{tabular}{lcccc}
\hline Flesh color & $\mathrm{n}$ & DPPH $(\mu \mathrm{mol}$ TE/g FW $)$ & ORAC $(\mu \mathrm{mol}$ TE/g FW $)$ & TPC $(\mathrm{mg} \mathrm{GAE} / \mathrm{g} \mathrm{FW})$ \\
\hline Pinkish & 16 & $2.46 \pm 1.40^{\mathrm{a}}$ & $37.74 \pm 13.15^{\mathrm{a}}$ & $1.11 \pm 0.42^{\mathrm{a}}$ \\
Pink to red & 21 & $3.13 \pm 1.37^{\mathrm{a}}$ & $41.33 \pm 16.63^{\mathrm{a}}$ & $1.30 \pm 0.62^{\mathrm{a}, \mathrm{c}}$ \\
Dark red & 70 & $3.26 \pm 1.29^{\mathrm{a}}$ & $47.41 \pm 14.52^{\mathrm{a}}$ & $1.45 \pm 0.42^{\mathrm{a}, \mathrm{c}}$ \\
Dark to very dark red & 35 & $3.32 \pm 1.35^{\mathrm{a}}$ & $44.63 \pm 23.08^{\mathrm{a}}$ & $1.59 \pm 0.45^{\mathrm{b}, \mathrm{c}}$ \\
Very dark red & 40 & $3.55 \pm 1.41^{\mathrm{a}}$ & $44.29 \pm 17.55^{\mathrm{a}}$ & $1.53 \pm 0.48^{\mathrm{b}, \mathrm{c}}$ \\
Mean & & $3.25 \pm 1.29$ & $44.64 \pm 18.28$ & $1.45 \pm 0.53$ \\
\hline
\end{tabular}

Means within a column with the same letter are not significantly different (Tukey's HSD test, $P \leq 0.05$ ).

The color of cherry fruits is attributed mainly to polyphenol concentration, especially to anthocyanin content, which was not measured in this study. Color development is influenced mainly by the concentration and distribution of various anthocyanins in the skin [7]. Both skin and pulp coloration are correlated with polyphenol concentration, especially anthocyanin content [30].

The samples were divided into five classes according to flesh color and its intensity: pinkish, pink to red, dark red, dark to very dark red and very dark red. As light-colored cherries are rare, they were included in the pinkish class. The mean TPC content and AC values were calculated for each class (Table 3 ). The results showed increasing values in TPC content and AC according to the intensity of the flesh color. The ANOVA, however, showed statistical differences only for the TPC content. Tukey's HSD test showed significant differences between the first class (pinkish fruits) and the two last classes (dark to very dark red and very dark red). For juice coloration there were three classes: pinkish, pink to red, and dark red. The mean TPC content and AC values were calculated for each class (Table 4). The results showed increasing TPC and AC values according to the intensity of the juice color. Statistical differences were observed for AC based on DPPH and TPC content. For the DPPH values, there were significant differences between pinkish and dark red juices. For TPC content, there were significant differences between pinkish juices and the two other classes (pink to red, and dark red). These results on the relationship between $\mathrm{AC}$ and the flesh and juice coloration accord with the previous results and it can therefore be concluded that the color of a fruit (skin, flesh or juice) can indicate its AC and TPC levels.

\subsubsection{Influence of the growing season}

A total of 69 cultivars were harvested at least twice in 2013 and in 2014. The comparison of the AC (ORAC and DPPH) and TPC values of these cultivars showed slightly higher values in 2013 than in 2014 (Table 5). Statistical analysis did not show significant differences for the DPPH and TPC values for the two growing seasons investigated. A highly significant difference was observed, however, for the AC revealed by ORAC. A 
Table 4

Mean antioxidant capacity (AC) determined by DPPH and ORAC assays ( $\mu \mathrm{mol} \mathrm{TE} / \mathrm{g} \mathrm{FW}$ ) and total phenolic compound (TPC) content (mg GAE/g FW) in cherries according to juice color

\begin{tabular}{lcccc}
\hline Juice color & $\mathrm{n}$ & DPPH $(\mu \mathrm{mol} \mathrm{TE} / \mathrm{g} \mathrm{FW})$ & ORAC $(\mu \mathrm{mol} \mathrm{TE} / \mathrm{g} \mathrm{FW})$ & TPC $(\mathrm{mg} \mathrm{GAE} / \mathrm{g} \mathrm{FW})$ \\
\hline Pinkish & 41 & $2.77 \pm 1.36^{\mathrm{a}}$ & $40.12 \pm 19.89^{\mathrm{a}}$ & $1.21 \pm 0.46^{\mathrm{a}}$ \\
Pink to red & 43 & $3.18 \pm 1.30^{\mathrm{a}, \mathrm{c}}$ & $45.12 \pm 17.87^{\mathrm{a}}$ & $1.47 \pm 0.52^{\mathrm{b}}$ \\
Dark red & 98 & $3.49 \pm 1.09^{\mathrm{b}, \mathrm{c}}$ & $46.32 \pm 17.31^{\mathrm{a}}$ & $1.54 \pm 0.57^{\mathrm{b}}$ \\
Mean & & $3.25 \pm 1.29$ & $44.64 \pm 18.28$ & $1.45 \pm 0.53$ \\
\hline
\end{tabular}

Means within a column with the same letter are not significantly different (Tukey's HSD test, $P \leq 0.05$ ).

Table 5

Comparison of the antioxidant capacity (AC) values determined by DPPH and ORAC assays ( $\mu \mathrm{mol}$ TE/g FW) and total phenolic compound (TPC) content (mg GAE/g FW) (mean \pm std deviation) obtained for the 69 cherry cultivars harvested in 2013 and 2014

\begin{tabular}{lccc}
\hline Parameter & $\mathrm{n}$ & 2013 & 2014 \\
\hline DPPH $(\mu \mathrm{mol} \mathrm{TE} / \mathrm{g} \mathrm{FW})$ & 69 & $4.05 \pm 2.65^{\mathrm{a}}$ & $3.80 \pm 2.33^{\mathrm{a}}$ \\
ORAC $(\mu \mathrm{mol} \mathrm{TE} / \mathrm{g} \mathrm{FW})$ & 69 & $59.64 \pm 33.49^{\mathrm{a}}$ & $41.48 \pm 24.52^{\mathrm{b}}$ \\
TPC $(\mathrm{mg} \mathrm{GAE} / \mathrm{g} \mathrm{FW})$ & 69 & $1.83 \pm 1.32^{\mathrm{a}}$ & $1.81 \pm 1.02^{\mathrm{a}}$ \\
\hline
\end{tabular}

Means within a row with the same letter are not significantly different $(t$-test, $P \leq 0.05)$.

significant effect of harvest year on AC (ORAC) and on TPC levels has been observed in other berries and small fruits [31, 32]. Researchers attribute these TPC and AC differences to changes in environmental conditions, such as temperature, water availability (drought or precipitation), light intensity, salinity and pollination. According to [32], the differences among harvest years could be explained by variation in weather conditions in the growing seasons, such as differences in rainfall and the number of frosts. Our results appear to corroborate this trend, given that climatic records (http://statbel.fgov.be) show that rainfall and number of days with negative temperatures were higher in 2013 than in 2014.

\subsection{Principal component analysis}

The AC (ORAC and DPPH) and TPC content were analyzed using Principal Component Analysis (PCA). The first two principal components (PCs) explained the totality of the variance. The score plot in Fig. 1 shows the distribution of the cherry cultivars along PC-1 and PC-2, which explained $91 \%$ and $9 \%$ the variance, respectively. The loading plots (not shown) showed that the AC revealed by DPPH values and TPC content were highly correlated with PC-1 and PC-2, respectively. Given the very high positive coefficient, the two components could be considered as a measure of these variables.

Initially, samples appeared to be gathered in the center of the plot, with some of them extending along the PC-1 and several along the PC-2. The analysis of sample distribution by cultivar type (P. avium, P. cerasus and $P . \times$ avium) highlighted a certain amount of grouping within the plot, with P. cerasus samples mostly extending along the PC-2, mainly in the upper part of the plot (positive values). In contrast, the P. avium samples formed a group that extended mainly along the PC-1. Finally, the $P . \times$ avium cultivars, derived from unspecified breeding between both species, were diffused among the samples in the center of the plot.

Taking into account the distribution of the samples and the analysis of the components, the results of the PCA plot showed that the sour cherry cultivars were characterized by high TPC content. Cultivars with the highest second component value (cultivars surrounded by a dotted circle) were essentially those belonging to the 'Griotte family', which is a group of sour cherries with high TPC content. They are characterized by their red to dark red 


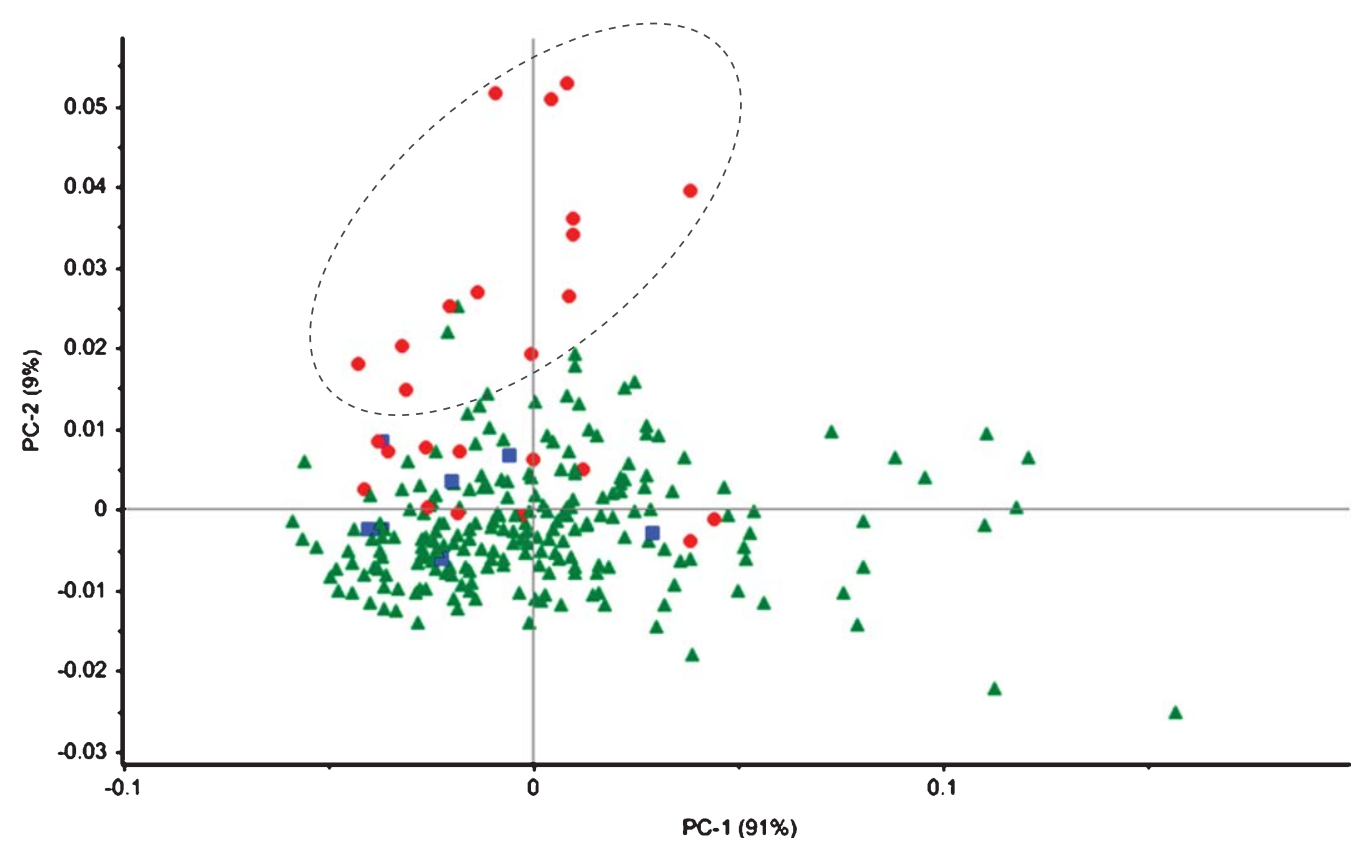

Fig. 1. Score plot of the 245 cherry samples along principal components 1 (PC-1) and 2 (PC-2) using three variables (ORAC, DPPH, and total phenolic compound $[$ TPC] content values). (ם) Prunus $\times$ avium, $(\bullet)$ P. cerasus, $(\mathbf{\Delta})$ P. avium.

color and their relatively high levels of acidity and bitterness. Given their sensory and chemical characteristics, they are usually used in the preparation of jam, beer and alcohol products.

\subsection{Relationship between agronomic characteristics and antioxidant capacity}

Given their detailed descriptions (country of origin and agronomic characterization), the 182 sweet cherry samples from the orchard growing commercial cherries were analyzed separately. Correlations between all variables (agronomic and chemical variables) were calculated to identify a possible relationship between the sensory and agronomic characteristics and the AC of the cultivars. All the coefficients of correlation were less than 0.6. The highest correlations were observed between firmness and maturity date $(r=-0.53 ; p$-value $<0.01)$ and between cracking and weight $(r=0.48 ; p$-value $<0.01)$. Correlations between weight, on the one hand, and firmness and maturity, on the other, were slightly lower, but also significant ( $r=-0.31$ and $r=0.30$, respectively; $p$-value $<0.01)$. No relevant relationship between the sensory and agronomic characteristics and the AC of the cultivars was identified, with all the correlation coefficients being very low (lower than 0.3 ). Only the correlations between weight, on the one hand, and DPPH values and TPC content $(r=-0.22 ; p$-value $<0.01)$, on the other, were significant.

The samples were subsequently subjected to PCA. An initial PCA was conducted taking into account the variables related to AC (ORAC and DPPH values) and TPC content. As observed previously, the first two components explained the totality of the variance (95\% and 5\% for PC-1 and PC-2, respectively). As previously observed, the two components were related mainly to the AC revealed by DPPH values and TPC content for PC-1 and PC-2, respectively. The analysis of the distribution of the cultivars did not show any differentiation or specific structure among the samples. The absence of differentiation by country of origin was confirmed by an ANOVA. Based on the data available, four main groups of origin (Canada, USA, Europe and Iran) were established for the 
analysis. The results did not allow any differentiation according to origin for any variable ( $p$-value $=0.769,0.184$ and 0.824 for DPPH, ORAC and TPC content values, respectively; data not shown). The absence of differentiation by origin suggests that the commercial cultivars grown worldwide have similar nutritional profiles in terms of $\mathrm{AC}$ and TPC content. This statement relates to the AC of the cultivars, however, and not to specific components, such as specific anthocyanins and phenolic compounds, implied in the AC measured here.

A second PCA was conducted taking into account the five agronomic parameters (sugar, firmness, maturity, weight, and cracking), in addition to the variables related to the AC (DPPH, ORAC and TPC content; figure not shown). The first two components explained $93 \%$ of the variance. A bi-dimensional plot was designed and the distribution of the cherry cultivars along PC-1 and PC-2 was analyzed. The first component, which explained $79 \%$ of the variance, showed that the AC revealed by DPPH values was the variable with the largest positive coefficient. The second component explained $14 \%$ of the variance and highlighted the 'cracking' variable. The analysis of the distribution of the cultivars did not allow the identification of some specific groups among the samples. Samples gathered together in a large and unique group, with some of them extending along the first component.

\section{Conclusions}

This study was conducted to analyze the TPC content and AC of a large range of sweet and sour cherry cultivars in our collections in a unique exercise based on using the same methodology and working in one laboratory. Significant variability in TPC content and AC among cultivars was shown. The results revealed a differentiation between the cherry types $(P$. avium, $P$. cerasus and $P . \times$ avium $)$ present in our orchards. The sour cherry cultivars had higher TPC content and AC values (revealed by both ORAC and DPPH assays) than the sweet cherries. They therefore represent a significant source of bioactive compounds and natural antioxidants and might attract new interest in evaluating their status as 'functional food', especially by the fruit industry.

Our results also showed that dark red fruits had significantly higher levels of TPCs and AC. The results suggested that the color parameter could be an indicator of fruit quality in terms of TPC content. The precise quantification of polyphenols, especially anthocyanins, however, was not done in this study. Further investigation needs to be done on sweet and sour cherries with a large range of skin and pulp coloration in order to determine the polyphenols and, in particular, the anthocyanins involved in the coloration of fruits in relation to their AC.

The large variability in terms of TPC content and AC revealed in this study probably reflects the large variability in our collections in terms of cherry types and morphological characteristics (mainly coloration). It is likely that our collections also have a very large range of other bioactive components, such as anthocyanins and vitamin C. The conservation of these collections is therefore essential in order to maintain a large genetic diversity for meeting future challenges. In addition, given the health benefits of cherries and the positive effect of their bioactive components on human diseases, further investigation should be carried out in order to better characterize our cherry genetic resources and to evaluate fruits with a high nutritional quality intended for direct consumption, for processing or for breeding purposes.

\section{References}

[1] Díaz-Mula HM, Castillo S, Martínez-Romero D, Valero D, Zapata PJ, Guillén F, et al. Sensory, nutritive and functional properties of sweet cherry as affected by cultivar and ripening stage. Food Sci Technol Int. 2009;15(6):535-43.

[2] Garcia-Montiel F, Serrano M, Matinez-Romero D, Alburquerque N. Factors influencing fruit set and quality in different sweet cherry cultivars. Span J Agric Res. 2010;8(4):1118-28.

[3] Serrano M, Guillén F, Martínez-Romero D, Castillo S, Valero D. Chemical constituents and antioxidant activity of sweet cherry at different ripening stages. J Agric Food Chem. 2005;53(7):2741-5.

[4] Usenik V, Fabčič J, Štampar F. Sugars, organic acids, phenolic composition and antioxidant activity of sweet cherry (Prunus avium L.). Food Chem. 2008;107(1):185-92. 
[5] Ballistreri G, Continella A, Gentile A, Amenta M, Fabroni S, Rapisarda P. Fruit quality and bioactive compounds relevant to human health of sweet cherry (Prunus avium L.) cultivars grown in Italy. Food Chem. 2013;140(4):630-8.

[6] Blando F, Gerardi C, Nicoletti I. Sour cherry (Prunus cerasus L.) anthocyanins as ingredients for functional foods. J Biomed Biotechnol. 2004;2004(5):253-8.

[7] Gao L, Mazza G. Characterization, quantification, and distribution of anthocyanins and colorless phenolics in sweet cherries. J Agric Food Chem. 1995;43(2):343-6.

[8] Pedisić S, Levaj B, Dragović-Uzelac V, Škevin D, Skendrović Babojelić M. Color parameters and total anthocyanins of sour cherries (Prunus cerasus L.) during ripening. Agric Conspec Sci. 2009;74(3):259-62.

[9] Wang H, Nair MG, Strasburg GM, Booren AM, Gray JI. Antioxidant polyphenols from tart cherries (Prunus cerasus L.). J Agric Food Chem. 1999;47(3):840-4.

[10] Kim DO, Heo HJ, Kim YJ, Yang HS, Lee CY. Sweet and sour cherry phenolics and their protective effects on neuronal cells. J Agric Food Chem. 2005;53(26):9921-7.

[11] Chaovanalikit A, Wrolstad RE. Total anthocyanins and total phenolics of fresh and processed cherries and their antioxidant properties. J Food Sci. 2003;69(1):67-72.

[12] Seeram NP, Momin RA, Nair MG, Bourquin LD. Cyclooxygenase inhibitory and antioxidant cyanidin glycosides in cherries and berries. Phytomedicine 2001;8(5):362-9.

[13] Kang SY, Seeram NP, Nair MG, Bourquin LD. Tart cherry anthocyanins inhibit tumor development in Apc(Min) mice and reduce proliferation of human colon cancer cells. Cancer Lett. 2003;194(1):13-9.

[14] Tall JM, Seeram NP, Zhao C, Nair MG, Meyer RA, Raja, SN. Tart cherry anthocyanins suppress inflammation-induced pain behavior in rat. Behav Brain Res. 2004;153(1):181-8.

[15] Ferretti G, Bacchetti T, Belleggia A, Neri D. Cherry antioxidants: From farm to table. Molecules. 2010;15(10):6993-7005.

[16] McCune ML, Kubota C, Stendell-Hollis NR, Thomson CA. Cherry and health: A review. Crit Rev Food Sci Nut. 2011;51(1):1-12.

[17] Frankel EN, Finley JW. How to standardize the multiplicity of methods to evaluate natural antioxidants. J Agric Food Chem. 2008;56(13):4901-8.

[18] Rautiainen S, Larsson S, Virtamo J, Wolk A. Total antioxidant capacity of diet and risk of stroke: A population-based prospective cohort of women. Stroke. 2012;43(2):335-40.

[19] Tabart J, Franck T, Kevers C, Pincemail J, Sereyn D, Defraigne J-O, et al. Antioxidant and anti-inflammatory activities of Ribes nigrum extracts. Food Chem. 2012;131(4):1116-22.

[20] Sipel A, Kevers C, Pincemail J, Grygiel PG, Defraigne J-O, Dommes J. Sample dilution influences the determination of antioxidant capacity in food. How to minimize it? Food Anal Method. 2013;6(5):1485-91.

[21] Kevers C, Sipel A, Pincemail J, Dommes J. Antioxidant capacity of hydrophilic food matrices: Optimization and validation of ORAC assay. Food Anal Methods. 2014;7(1):409-16.

[22] Melicháčová S, Timoracká M, Bystrická J, Vollmannová A, Čéry J. Relation of total antiradical activity and total polyphenol content of sweet cherries (Prunus avium L.) and tart cherries (Prunus cerasus L.). Acta Agric Slov. 2010;95(1):21-8.

[23] Viljevac M, Dugalić K, Jurković V, Mihaljević I, Tomaš V, Puškar B, et al. Relation between polyphenols content and skin colour in sour cherry fruits. J Agric Sci. 2012;57(2):57-67.

[24] Serrano M, Díaz-Mula HM, Zapata PJ, Castillo S, Guillén F, Martínez-Romero D, et al. Maturity stage at harvest determines the fruit quality and antioxidant potential after storage of sweet cherry cultivars. J Agric Food Chem. 2009;57(8):3240-6.

[25] Mozetiĉ B, Trebše P, Hribar J. Determination and quantification of anthocyanins and hydroxycinnamic acids in different cultivars of sweet cherries (Prunus avium L.) from Nova Gorica Region (Slovenia). Food Technol Biotechnol. 2002;40(3):207-12.

[26] Serra AT, Duarte RO, Bronze MR, Duarte CMM. Identification of bioactive response in traditional cherries from Portugal. Food Chem. 2011;125(2):318-25.

[27] Prvulović D, Malenčić D, Popović M, Ljubojević M, Ognjanov V. Antioxidant properties of sweet cherries (Prunus avium L.) - Role of phenolic compounds. World Acad Sci Eng Technol. 2011;59:1149-52.

[28] Liu Y, Liu X., Zhong F, Tian R, Zhang K, Zhang X, et al. Comparative study of phenolic compounds and antioxidant activity in different species of cherries. J Food Sci. 2011;76(4):633-8.

[29] Vangdal E, Slimestad R. Methods to determine antioxidative capacity in fruit. J Fruit Ornam Plant Res. 2006;14(2):123-31.

[30] Pérez-Sánchez R, Gómez-Sánchez MA, Morales-Corts MR. Description and quality evaluation of sweet cherries cultured in Spain. J Food Qual. 2010;33(4):490-506.

[31] Howard LR, Clark JR, Brownmiller C. Antioxidant capacity and phenolic content in blueberries as affected by genotype and growing season. J Sci Food Agr. 2003;83(12):1238-47.

[32] Alfaro S, Mutis A, Palma R, Quiroz A, Seguel I, Scheuermann E. Influence of genotype and harvest year on polyphenol content and antioxidant activity in murtilla (Ugni molinae Turcz) fruit. J Soil Sci Plant Nutr. 2013;13(1):67-78. 